\title{
The Effect of Triclosan Adaptation on Antimicrobial Resistance among Clinical Escherichia coli Isolates from Egyptian Patients
}

\author{
Eman A. El-Masry ${ }^{1,2 *}$ (D) Ahmed E. Taha ${ }^{1,3}$ and Soma E. Ajlan ${ }^{2}$ \\ ${ }^{1}$ Department of Pathology, Microbiology and Immunology Unit, College of Medicine, \\ Jouf University, Al-Jouf, Saudi Arabia. \\ ${ }^{2}$ Department of Medical Microbiology and Immunology, College of Medicine, Menoufia University, Egypt. \\ ${ }^{3}$ Department of Medical Microbiology and Immunology, Faculty of Medicine, \\ Mansoura University, Mansoura, Egypt.
}

\begin{abstract}
There is a possible link between exposure to Triclosan (TCS) and changes in antimicrobial susceptibility. The change in the tolerance of clinical Escherichia coli $(n=45)$ isolates to the biocide TCS, changes in antibiotic resistance and differences in the efflux pump mechanism were analyzed. $45 \mathrm{E}$. coli isolates were obtained. The minimum inhibitory concentration (MIC), the minimum bactericidal concentration (MBC) of TCS, and the expression of four efflux pump encoding genes in antibiotic resistant isolates were determined before and after TCS adaptation. The number of TCS-tolerant isolates was 11 (24.4\%). After adaptation, the percentage of tolerant isolates increased to $42.2 \%(n=19)$. A significant change $(p<0.05)$ in antimicrobial resistance of the tested isolates $(n=45)$ before and after TCS adaptation was detected for ceftazidime, ceftriaxone, ertapenem, imipenem, amikacin, gentamicin, tobramycin, ciprofloxacin, levofloxacin and doxycycline. Among the new TCS tolerant isolates $(n=8)$. there was an increase in TCS MIC as well as the MBC after TSC adaptation. The adapted isolates exhibited a significant increase in the expression of $m d f A$ and norE genes $(p=<0.001)$. There is a strong correlation between efflux pump gene overexpression and susceptibility to TCS and other antimicrobials.
\end{abstract}

Keywords: Triclosan, Efflux pump, MIC, Cross-resistance, Escherichia coli

*Correspondence: ealmasry@ju.edu.sa; 00966504352680

(Received: August 23, 2021; accepted: November 09, 2021)

Citation: El-Masry EA, Taha AE, Ajlan SE. The Effect of Triclosan Adaptation on Antimicrobial Resistance among Clinical Escherichia coli Isolates from Egyptian Patients. J Pure Appl Microbiol. 2021;15(4):2394-2402. doi: 10.22207/JPAM.15.4.64

(C) The Author(s) 2021. Open Access. This article is distributed under the terms of the Creative Commons Attribution 4.0 International License which permits unrestricted use, sharing, distribution, and reproduction in any medium, provided you give appropriate credit to the original author(s) and the source, provide a link to the Creative Commons license, and indicate if changes were made. 


\section{INTRODUCTION}

Triclosan (TCS) (2,4,4-trichloro-2-hydroxydiphenyl ether) is a broad spectrum non-antibiotic antimicrobial agent that is a common ingredient in more than 200 consumer products, such as detergents, soaps, disinfectants, toothpaste, and shower gels. ${ }^{1}$ TCS is characterized by a wide activity range against several microorganisms, for example, Staphylococcus aureus and Escherichia coli. ${ }^{2,3}$

TCS, like other biocides, is not used to treat host infections, and as a result, the regulations on use of this compound are not as strict as they are for antibiotics. Biocides are widely used without restrictions in many fields, such as the food industry, household hand-cleaning chemicals, and dental washing. Biocides may select for antibiotic-resistant microorganisms. ${ }^{4}$ Even at low concentrations, TCS has been shown to cause antibiotic resistance via different mechanisms. ${ }^{4,5}$

Previous studies investigated the potential link between clinical isolates exposed to biocides, such as TCS, and altered antimicrobial sensitivity and indicated that repeated exposure to sublethal concentrations of biocides can contribute to the spread of antimicrobial resistance. Studies on Staphylococcus aureus and E. coli showed that tetracycline and chloramphenicol resistance was elevated tenfold after exposure to TCS..$^{2,6}$ TCS is assumed to exert pressure on the bacterial community, conferring bacterial resistance to the microorganisms, raising concerns about the possibility of cross-resistance between antimicrobials or antibiotics. ${ }^{7,8}$

Several mechanisms appear to drive antimicrobial resistance after the adaptation of TCS. The overproduction of efflux pumps is regarded as one of the most prevalent biocides resistance mechanisms. ${ }^{8}$ Overproduction of efflux pumps is associated with low-level resistance to biocides, and several classes of antibiotics, such as fluoroquinolones, $\beta$-lactams, tetracyclines and macrolides. ${ }^{9}$ Efflux pumps enable bacteria to physically remove an ingredient from the intracellular space by pumping it through the membrane back into the surrounding environment. This mechanism has proved to be effective against several antimicrobials as well as biocides such as TCS. ${ }^{9,10}$ Examples of these efflux pumps are the resistance nodulation division (RND) family, the staphylococcal multi-resistance (SMR) family and the significant facilitator super (MFS) family. ${ }^{11,12}$

Among the systems investigated for biocide extrusion, TolC, AcrAB, TolC AcrEF and EmrE from E. coli $i^{13-15}$ and MexCD-OprJ, MexABOprM, as well as MexEF-OprN from P. aeruginosa ${ }^{16}$ are the most highlighted. The majority of nonspecific efflux pumps can remove antibiotics from an intracellular location and thus cause resistance. Therefore, when the bacteria acquire a nonspecific efflux pump via horizontal gene transfer after TCS exposure, these bacteria frequently develop antibiotic resistance as well. ${ }^{17,18}$

As several biosides are used nowadays, the risk of inappropriate use of these biosides can lead to the spread of antibiotic-resistant bacteria. For this reason, more research is needed to further investigate this topic. In particular, studies on the possible role of biocides in the development of antibiotic resistance with an Egyptian setting are un-common. This study seeks to address this point.

\section{PATIENTS AND METHODS}

The current study was conducted in the Department of Medical Microbiology and Immunology in the Central Laboratory, Faculty of Medicine, Menoufia University.

Bacterial isolation and antimicrobial susceptibility

45 E. coli isolates were obtained from Menoufia University hospitals from March 2019 to March 2020. Each isolate was obtained from a patient suffering from an infection, such as a respiratory tract or urinary tract infection or bacteremia. Samples were cultured on nutrient, blood, and MacConkey agar media. Plates were incubated at $37^{\circ} \mathrm{C}$ for $24 \mathrm{~h}$. Identification was done using selective media and conventional biochemical methods as described by El-Hadedy and El-Nour. ${ }^{19}$ Isolates were stored in tryptic soy broth supplemented with $16 \%$ glycerol and frozen at $-80^{\circ} \mathrm{C}$. The study was approved by the local ethics council at the Faculty of Medicine Menoufia University, and verbal consent was obtained from each patient before sampling.

Antimicrobial susceptibility testing was conducted using agar dilution, along with adherence to the guidelines of the Clinical and Laboratory Standards Institute (CLSI, 2009). ${ }^{20}$ 
Detecting the minimum inhibitory TCS concentration (MIC) as well as minimum bactericidal concentration (MBC) via the method of broth dilution

The TCS MIC for each of tested isolates was determined using broth microdilution method using a microtitration plate according to the CLSI guidelines. ${ }^{20}$ In each plate had a growth control well (postive control) and uninoculated well as (negative control). the plates were incubated for $24 \mathrm{~h}$ at $37^{\circ} \mathrm{C}$. The lowest concentration of antibiotic that completely inhibited the bacterial growth as indicated by no visible turbidity in the well in comparison with the positive and negative controls was accepted as the MIC.

After determination of the MIC, the wells that showed growth inhibion were subcultered onto Mueller-Hinton ( $\mathrm{MH}$ ) agar plates to determine the minimum bactericidal concentration (MBC). The MBC was defined as the lowest concentration of TCS required to kill the bacteria after culture and incubation $24 \mathrm{~h}$ at $37^{\circ} \mathrm{C}$. All of these determinations was carried out in triplicate According to Curiao et al., ${ }^{21}$ isolates were considered tolerant if the TCS MIC was higher than $7.5 \mu \mathrm{g} / \mathrm{ml}-1$

Adaption to an increased TCS concentration

The adaptive isolation response to TCS was tested by daily exposure to gradually increasing sub-lethal concentrations of TCS for seven days according to the method described by Soumet et al. ${ }^{22}$

The experiment started with concentration of $0.5 \times \mathrm{MBC}$ of TCS in $\mathrm{MH}$ broth which was incubated for $24 \mathrm{~h}$ at $37^{\circ} \mathrm{C}$. Once bacterial growth was detected, $100 \mu$ l of the bacterial suspension was transferred to fresh MHB (10 ml) supplemented with a higher TCS concentration (concentrations used ranged from 1 to $10 \mu \mathrm{g} / \mathrm{ml}$ and increased by $1 \mu \mathrm{g} / \mathrm{ml}$ per day). This procedure continues until no growth is detected after incubation for $24 \mathrm{~h}$ at $37^{\circ} \mathrm{C}$. When no growth is detected, the previous concentration is used as the endpoint.

The bacteria were spread from the last tube with the recorded bacterial growth, with a loop $(10 \mu \mathrm{l})$ on $\mathrm{MH}$ agar, and incubated for $24 \mathrm{~h}$ at $37^{\circ} \mathrm{C}$ to confirm growth as well as to allow storage. As a control, a bacterial suspension $(100 \mu \mathrm{l})$ was added to $\mathrm{MH}$ broth $(10 \mathrm{ml})$ and the process above used but in the absence of TCS.

\section{Determining efflux pump genes by quantitative Reverse Transcription PCR (RT-qPCR)}

Quantitative reverse transcription PCR assays for the efflux pumps encoded via the $m d f A$, $a c r B$, norE, and yih $V$ genes were investigated using the primers previously recommended by Huguet et al. ${ }^{23}$

RNA was extracted utilizing the RNeasy ${ }^{\circledR}$ Mini Kit (Qiagen, Hilden, Germany), according to the manufacturer's instructions with minor modifications. The bacterial cells were disrupted using lysosome (Sigma-Aldrich) as well as proteinase K (Qiagen). RNA purification using the RNase-Free DNase Set Kit (Qiagen) was performed to remove any residual DNA. The quantity and quality of the extracted RNA were measured by a Nanodrop spectrophotometer (Nanodrop Technologies).

Afterwards, the RNA was transcribed into cDNA via a cDNA power synthesis kit (First Strand cDNA Synthesis Kit) (Thermofisher Scientific, Applied Biosystems, USA), as recommended by the manufacturer. The synthesized cDNA was used as a real-time PCR template, utilizing SYBR Green II master blend (QuantiTect SYBR Green PCR Kit, Applied Biosystems, USA) in Applied Biosystems 7500, software version 2.0.1. (Applied Biosystems, USA).

Quantitative PCR was carried out on a Chromo4 ${ }^{\mathrm{TM}}$ Real-Time Detector (Bio-Rad, Marnes-

Table 1. Primers and annealing temperatures utilized in qRT-PCR

\begin{tabular}{lccc}
\hline \multicolumn{2}{c}{ Forward } & Reverse & Annealing temp. \\
\hline acrB & 5/-GAAGAGCACGCACCACTACAC-3 & 5/-GCAGACGCACGAACAGATAGG-3 & 55 \\
mdfA & 5/-TTTATGCTTTCGGTATTGG-3/ & 5/-GAGATTAAACAGTCCGTTGC-3/ & 52 \\
norE & 5/-TCGCAGGACATCAGATTG-3/ & 5/-CAGACACCCACCATAAGC-3/ & 55 \\
yihV & 5/-GGCTATCATCCTCGTCTTCC-3/ & 5/-GCGTCATCCACCAGTAACC-3/ & 54 \\
gapA & 5/-GGACGAAGTTGGTGTTGAC-3/ & 5/-TTCTGAGTAGCGGTAGTAGC-3 & 54 \\
\hline
\end{tabular}


la-Coquette, France) for the four efflux pump genes $m d f A, a c r B$, norE, and yihV. The gapA gene was employed as a housekeeping gene( as it did not exhibit any significant variation in expression among the samples) to normalize the levels of gene expression of acrB, $m d f A$, norE and yihV. For each gene, the reactions were performed in duplicate. The total volume of the reaction was $20 \mu \mathrm{l}$ containing $10 \mu \mathrm{l}$ Power SYBR ${ }^{\circledR}$ GREEN PCR Master Mix $5 \mu \mathrm{l}$ cDNA, $1 \mu \mathrm{l}$ of each primer $(0 \bullet 3$ $\mu \mathrm{mol} \mathrm{I}-1$ final concentration) and $3 \mu \mathrm{l}$ sterile water. After an initial step $\left(94^{\circ} \mathrm{C}\right.$ for $\left.7 \mathrm{~min}\right)$, the thermal cycling protocol was as follows: 40 cycles of PCR for $15 \mathrm{~s}$ at $95^{\circ} \mathrm{C}$ for denaturation, for $15 \mathrm{~s}$ at 52 or $55^{\circ} \mathrm{C}$ for annealing, and for $15 \mathrm{~s}$ at $72^{\circ} \mathrm{C}$ for extension. Data were analyesd as performed by Huguet et al. ${ }^{23}$ The primers that were used in the current study are displayed in Table 1.

The qRT-PCR efficiencies were calculated from the slope of a linear regression model, for each pair of primers when the reaction efficiency is estimated at $(E)=10\left(-1 /\right.$ slope) ${ }^{24,25}$ For serial concentrations of CDNA, the $\mathrm{Ct}$ calculated the calibration curve. The rotor gene $Q$ v. 2.3.1 program (QIAGEN-Germany) was employed for the interpretation of the findings. The relative expressions of $a c r B, m d f A$, norE, and yihV were completed through a comparative $\mathrm{Ct}$ method, ${ }^{26}$ in which the total target genes are normalized to a housekeeping reference gene (gapA). Each test was performed using a melting curve analysis to validate the accuracy of amplification and the absence of primer dimers.

\section{Statistical analysis}

Statistical analysis was conducted by SPSS, version 20; SPSS Inc., Chicago, Illinois, USA. Data were recorded, tabulated, and analyzed using Excel software for Windows. The susceptible and resistant strain distributions, before the following adaptation have been compared using the Chisquare test. A p-value $<0.05$ was considered to be statistically significant.

\section{RESULTS}

A total of $45 \mathrm{E}$. coli isolates were obtained. The MIC values for TSC varied from 1 to $64 \mu \mathrm{g} /$ $\mathrm{ml}$. Moreover, among these E. coli isolates, $24.4 \%$ $(n=11)$ were tolerant to TCS (Table 2). After adaptation, another eight $(17.7 \%)$ isolates (named as E1 to E8), became tolerant to TCS. The total number of tolerant isolates became 19 (42.2\%).

Table 2. Minimum inhibitory concentration (MIC) of TCS for the $45 \mathrm{E}$. coli isolates

\begin{tabular}{lcc}
\hline TCS Concen. & \multicolumn{2}{c}{ TCS (MIC) } \\
\cline { 2 - 3 }$(\mu \mathrm{g} / \mathrm{ml})$ & $\begin{array}{c}\text { Before } \\
\text { adaptation } \\
\text { No (\%) }\end{array}$ & $\begin{array}{c}\text { After } \\
\text { adaptation } \\
\text { No (\%) }\end{array}$ \\
\hline 1 & $4(8.9)$ & $1(2.2)$ \\
2 & $13(28.9)$ & $10(22.2)$ \\
4 & $17(37.8)$ & $15(33.3)$ \\
8 & $2(4.4)$ & $2(4.4)$ \\
16 & $7(15.6)$ & $14(31.1)$ \\
32 & $2(4.4)$ & $3(6.7)$ \\
64 & 0 & 0 \\
\hline
\end{tabular}

Table 3. Minimum inhibitory TCS concentration (MIC) and minimum bactericidal concentration (MBC) of tolerant E. coli isolates after adaptation $(\mathrm{N}=8)$

\begin{tabular}{|c|c|c|c|c|}
\hline \multirow{2}{*}{$\begin{array}{l}\text { Triclosan } \\
\text { resistant isolates } \\
\text { after adaptation } \\
(n=8)\end{array}$} & \multicolumn{2}{|c|}{ TCS MIC $(\mu \mathrm{g} / \mathrm{ml})$} & \multicolumn{2}{|c|}{ TCS MBC $(\mu \mathrm{g} / \mathrm{ml})$} \\
\hline & $\begin{array}{c}\text { Before } \\
\text { adaptation }\end{array}$ & $\begin{array}{c}\text { After } \\
\text { adaptation }\end{array}$ & $\begin{array}{c}\text { Before } \\
\text { adaptation }\end{array}$ & $\begin{array}{c}\text { After } \\
\text { adaptation }\end{array}$ \\
\hline E1 & 4 & 16 & 4 & 32 \\
\hline E2 & 2 & 16 & 4 & 32 \\
\hline E3 & 8 & 32 & 8 & 32 \\
\hline E4 & 4 & 16 & 4 & 16 \\
\hline E5 & 2 & 16 & 4 & 16 \\
\hline E6 & 4 & 32 & 4 & 64 \\
\hline E7 & 4 & 16 & 4 & 32 \\
\hline E8 & 4 & 16 & 4 & 32 \\
\hline
\end{tabular}

MIC (minimum inhibitory concentration), MBC (minimum bactericidal concentration). 
Among the eight TCS tolerant E. coli isolates after adaptation, there was an increase in TCS MIC as well as the MBC (Table 3).
A significant change $(p<0.05)$ in antimicrobial resistance of the tested isolates $(n=45)$ before and after TCS adaptation was

Table 4. Antimicrobial susceptibility among $45 \mathrm{E}$. coli isolates, before and after TCS adaptation

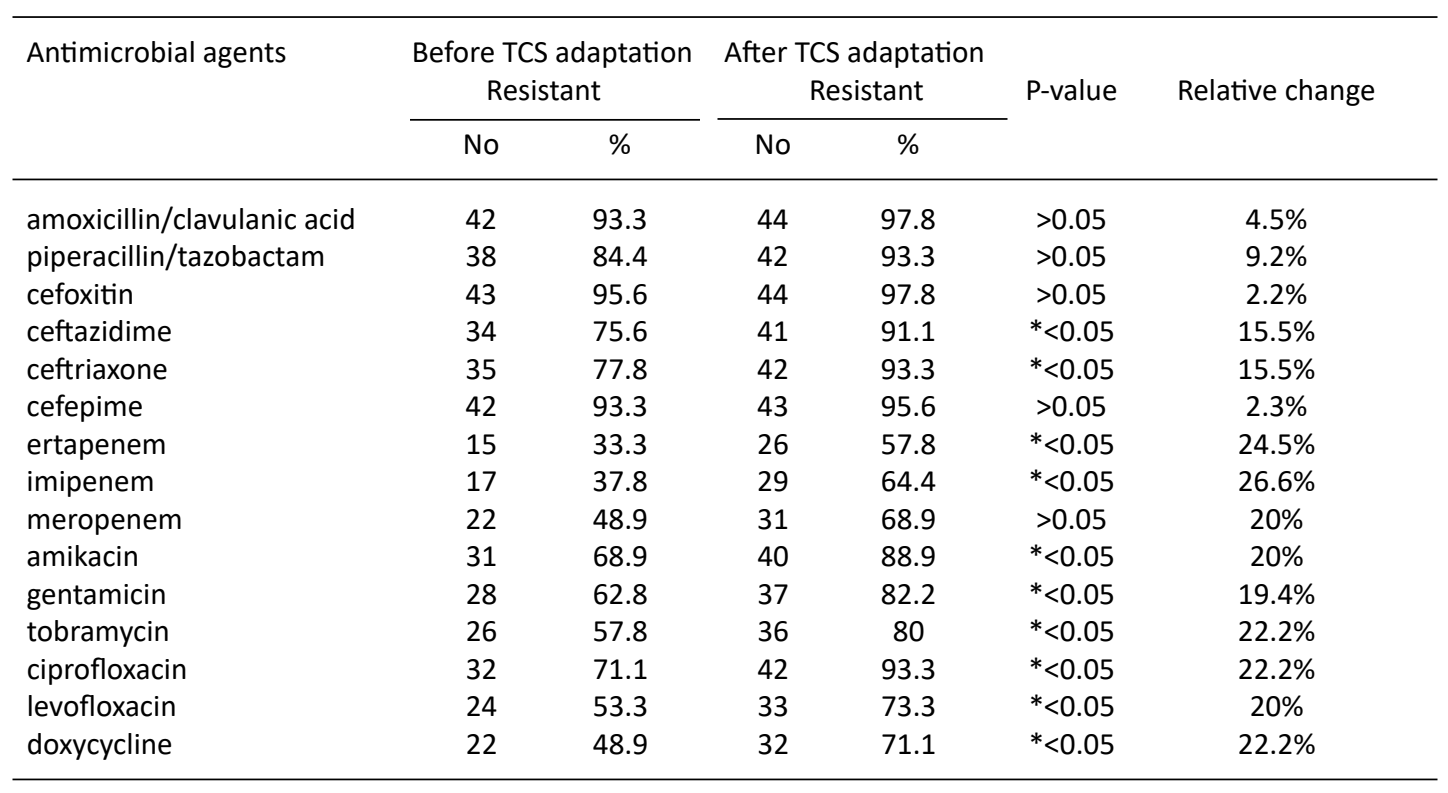

$* p<0.05$, statistically significant.

detected for ceftazidime, ceftriaxone, ertapenem, imipenem, amikacin, gentamicin, tobramycin, ciprofloxacin, levofloxacin and doxycycline.

Before the adaptation to TCS, the highest resistance level was recorded to cefoxitin (95.6\%) followed by amoxicillin/clavulanic acid (93.3\%), and finally cefepime (93.3\%). After adaptation, the resistance increased to $97.8 \%, 97.8 \%$, and $95.6 \%$, respectively (Table 4).

Table 6 shows that there was a significant elevation in the efflux pump gene expression for $m d f A$ and norE in the TCS-adapted isolates $(p<0.001)$

Table 5. Analysis of the relative gene expression of $E$. coli $(n=8)$ after TCS adaptation

\begin{tabular}{|c|c|c|c|c|c|c|c|c|}
\hline \multirow{3}{*}{ Isolates } & \multicolumn{8}{|c|}{ Relative gene expression } \\
\hline & \multicolumn{2}{|c|}{$a c r B$} & \multicolumn{2}{|c|}{$m d f A$} & \multicolumn{2}{|c|}{ norE } & \multicolumn{2}{|c|}{ yihV } \\
\hline & $\begin{array}{c}\text { Before } \\
\text { adaptation }\end{array}$ & $\begin{array}{c}\text { After } \\
\text { adaptation }\end{array}$ & $\begin{array}{c}\text { Before } \\
\text { adaptation }\end{array}$ & $\begin{array}{c}\text { After } \\
\text { adaptation }\end{array}$ & $\begin{array}{c}\text { Before } \\
\text { adaptation }\end{array}$ & $\begin{array}{c}\text { After } \\
\text { adaptation }\end{array}$ & $\begin{array}{c}\text { Before } \\
\text { adaptation }\end{array}$ & $\begin{array}{c}\text { After } \\
\text { adaptation }\end{array}$ \\
\hline E1 & 1 & 1 & 2.874 & 4.602 & 401.7 & 576.929 & 1.115 & 1.589 \\
\hline E2 & 1.076 & 1.114 & 2.953 & 6.055 & 1 & 1 & 0.985 & 1.343 \\
\hline E3 & 1 & 1.045 & 1.763 & 3.937 & 539.65 & 843.768 & 1.003 & 1.449 \\
\hline E4 & 1.194 & 1.706 & 2.985 & 7.626 & 63.9 & 63.9 & 1.728 & 2.098 \\
\hline E5 & 1 & 1.081 & 1 & 1 & 12.935 & 15.579 & 1.554 & 1.793 \\
\hline E6 & 1.076 & 1.259 & 3.919 & 7.495 & 435.879 & 943.321 & 1.025 & 1.128 \\
\hline E7 & 1.093 & 1.263 & 4.642 & 8.793 & 328.459 & 706.77 & 1 & 1.057 \\
\hline E8 & 1.125 & 1.558 & 5.829 & 7.307 & 679.51 & 984.418 & 0.659 & 1 \\
\hline
\end{tabular}


Table 6. Analysis of the relative gene expression of $E$. coli $(n=8)$ after TCS adaptation

\begin{tabular}{lcc}
\hline Gene & qRT-PCRFold Change [std error] & p-value \\
\hline acrB & $1.665[1.512$ to 1.814$]$ & 0.024 \\
mdfA & $2.426[2.275$ to 2.573$]$ & $<0.001^{*}$ \\
norE & $2.124[1.743$ to 1.915$]$ & $<0.001^{*}$ \\
yihV & $1.204[1.432$ to 1.715$]$ & 0.04 \\
\hline
\end{tabular}

* statistically significant

\section{DISCUSSION}

The role of biocides in the selection and the prevalence of antibiotic resistance has emerged recently. Therefore, several studies have focused on investigating the biocide susceptibility of clinical bacterial isolates..$^{27,28}$ One of the most fundamental methods causing antimicrobial resistance is the exposure of bacteria to sub-inhibitory antibiotic concentrations. Furthermore, bacteria tend to follow a similar path during adaption to biocides at sublethal concentrations. ${ }^{29-31}$

There is a growing concern that excessive use of TCS is the reason for the accelerated emergence of TCS tolerance among clinical isolates. Consequently, the existence of TCS-tolerant E. coli, S. aureus, Klebsiella pneumoniae, and Acinetobacter baumannii has been reported. ${ }^{32,33}$

Initially, eleven (24.4\%) of the 45 isolates showed an elevated MIC to TCS. After adaptation, the percentage of TCS tolerant isolates increased to $42.2 \%$ ( $n=19$ ) (Table 2).

A significant change $(p<0.05)$ in antimicrobial resistance of the tested isolates $(\mathrm{N}=45)$ before and after TCS adaptation was detected for ceftazidime, ceftriaxone, ertapenem, imipenem, amikacin, gentamicin, tobramycin, ciprofloxacin, levofloxacin and doxycycline (Table 4). Sonbol et al..$^{34}$ in his study reported a similar pattern of a significant increase in antibiotic resistance after adaptation to TCS, except that we did not detect a rise in the MIC values for amikacin and sulphamethoxazole/trimethoprim.

Many studies have examined the potential link between exposure of clinical isolates to biocides and the development of biocide resistance and any associated change in antimicrobial susceptibility.
Romanova et al. ${ }^{35}$ found that biocide-adapted Listeria monocytogenes had a 2 to 4 -fold elevation in MIC to gentamycin, kanamycin and novobiocin as compared with the wild type. Karmakar et al. ${ }^{1}$ reported a four-fold increase in MIC and MBC concentration of gatifloxacin among Aeromonas hydrophila and Edwardsiella tarda isolates after exposure to TCS. Other studies investigated a decrease in antibiotic susceptibility in $E$. coli, $P$ s. aeruginosa, Salmonella, and S. aureus after exposure to biocide or adaptation. ${ }^{36-40}$ These findings indicated that exposure to biocides could alter antibiotic susceptibility.

In E. coli, fluoroquinolone resistance occurs through several mechanisms - one being changes in the outer membrane porins (OMPs). These changes may be associated with overexpression of an efflux pump gene and can lead to reduced susceptibility to fluoroquinolones. ${ }^{41}$ The MFS, multi-drug, toxic compound extrusion (MATE), and RND families are chromosomedependent efflux systems, which are the main cause of resistance to fluoroquinolones..$^{42} \mathrm{OmpC}$ and $\mathrm{OmpF}$ from the porin family are examples of OMPs and efflux pumps that contribute to fluoroquinolone resistance. ${ }^{43} \mathrm{AcrB}, \mathrm{AcrF}$, and YhiV are RND family elements, while NorE is an example of the MATE family, and MdfA is from the MFS efflux pump family. ${ }^{43}$

In a study done by Zeng et al. ${ }^{11}$ on $E$. coli isolated from urine an increase in the overexpression of $y i h V, a c r B, a c r D$, and $m d f A$, all belonging to the MFS family was noted. Romanova et al. ${ }^{35}$ reported that the increase in MIC of biocides in adapted $L$. monocytogenes strains was due to the increased expression of efflux pumpencoding gene $\mathrm{mdrL}$. In another study conducted by Curiao et al. ${ }^{21}$ exposure to the biocide TCS resulted in cross-resistance to antimicrobials with overexpression of efflux pump gene regulators. Similar results of an increase in the expression of efflux gene pump were reported among biocide adapted E. coli, Serratia marcescens and Acinetobacter baumannii isolates. ${ }^{4-46}$

In brief, our results showed that repeated exposure to sub-lethal concentrations of TCS increased the expression of efflux genes which resulted in an altered bacterial susceptibility to antimicrobial compounds 


\section{CONCLUSION}

We concluded that stepwise exposure to sublethal concentration of TCS can be responsible for adaptive expesssion of mechanisms that affect efflux activity which in turn influences the bacterial susceptibility to different antimicrobials. More studies are needed to study the molecular mechanisms that are responsible for the increase in antimicrobial resistance among the biocide adapted E. coli isolates. As TCS disinfectants are used in uncontrolled way in Egyptian hospitals and may be a contributing factor for increasing antimicrobial resistance. A well planned longitudinal study is recommended to investigate the molecular changes before and after repeated exposure to the biocide TCS.

\section{ACKNOWLEDGMENTS}

The authors would like to thank the members of the Central Laboratory, Faculty of medicine- Menoufia University for their technical support. The authors also express their gratitude to Dr. Engy El-Ekhnawy, Pharmaceutical Microbiology, Faculty of Pharmacy, Tanta University, for her cooperation.

\section{CONFLICT OF INTEREST}

The authors declare that there is no conflict of interest.

\section{AUTHORS' CONTRIBUTION}

All authors listed have made a substantial, direct, and intellectual contribution to the work, and approved it for publication.

\section{FUNDING}

None.

\section{DATA AVAILABILITY}

The datasets generated during and/or analyzed during the current study are available from the corresponding author on reasonable request.

\section{ETHICS STATEMENT}

The study was approved by the local ethics committee at the Faculty of Medicine, Menoufia University, Egypt.

\section{INFORMED CONSENT}

Informed consent was taken from each patient before the study.

\section{REFERENCES}

1. Karmakar S, Abraham TJ, Kumar S, et al. Triclosan exposure induces varying extent of reversible antimicrobial resistance in Aeromonas hydrophila and Edwardsiella tarda. Ecotoxicol Environ Safety. 2019;180:309-316. doi: 10.1016/j.ecoenv.2019.05.010

2. Suller MTE, Rusell AD. Triclosan and antibiotic resistance in Staphylococcus aureus. J Antimicrob Chemother. 2000;46(1):11-18. doi: 10.1093/jac/46.1.11

3. Westfall C, Flores-Mireles AL, Robinson JI, et al. The widely used antimicrobial triclosan induces high levels of antibiotic tolerance in vitro and reduces antibiotic efficacy up to 100 -fold in vivo. Antimicrobial agents and chemotherapy. 2019; 63(5), e02312-18.

4. Yazdankhah SP, Scheie AA, Hoiby EA, et al. Triclosan and antimicrobial resistance in bacteria: an overview. Microbial Drug Resistance. 2006;12(2):83-90. doi: 10.1089/mdr.2006.12.83

5. Christensen EG, Gram L, Kastbjerg VG. Sublethal triclosan exposure decreases susceptibility to gentamicin and other aminoglycosides in Listeria monocytogenes. Antimicrob Agents Chemother. 2011;55(9):4064-4071. doi: 10.1128/AAC.00460-11

6. Yu BJ, Kim JA, Pan JG. Signature gene expression profile of triclosan-resistant Escherichia coli. J Antimicrob Chemother. 2010;65(6):1171-1177. doi: 10.1093/jac/ dkq114

7. Poole K. Mechanisms of bacterial biocide and antibiotic resistance. J App/ Microbiol. 2002;92(S1):55S-64S. doi: 10.1046/j.1365-2672.92.5s1.8.x

8. Warnke PH, Lott AJS, Sherry E, Wiltfang J, Podschun $R$. The ongoing battle against multi-resistant strains: in-vitro inhibition of hospital-acquired MRSA, VRE, Pseudomonas, ESBL E. coli and Klebsiella species in the presence of plant-derived antiseptic oils. Journal of Cranio-Maxillofacial Surgery. 2013;41(4):321-326. doi: 10.1016/j.jcms.2012.10.012

9. Levy SB. Active efflux, a common mechanism for biocide and antibiotic resistance. J Appl Microbiol. 2002;92(S1):65S-71S. doi: $10.1046 /$ j.13652672.92.5s1.4.x

10. Kern WV, Oethinger M, Jellen-Ritter AS, Levy SB. Non-target gene mutations in the development of fluoroquinolone resistance in Escherichia coli. Antimicrob Agents Chemother. 2000;44(4):814-820. doi: 10.1128/AAC.44.4.814-820.2000

11. Zeng $W, X u W, X u Y$, et al. The prevalence and mechanism of triclosan resistance in Escherichia coli isolated from urine samples in Wenzhou, China. Antimicrob Resist Infect Control. 2020;9(1):1-10. doi: 10.1186/s13756-020-00823-5

12. Piddock LJV. Clinically relevant chromosomally encoded multidrug resistance efflux pumps in bacteria. Clin Microbiol Rev. 2006;19(2):382-402. doi: 10.1128/ CMR.19.2.382-402.2006

13. Mcmurry LM, Oethinger M, Levy SB. Overexpression of marA, soxS, or acrAB produces resistance to triclosan 
in laboratory and clinical strains of Escherichia coli. FEMS Microbiol Lett. 1998;166(2):305-309. doi: 10.1111/j.1574-6968.1998.tb13905.x

14. Blanco P, Hernando-Amado S, Reales-Calderon JA, et al. Bacterial multidrug efflux pumps: much more than antibiotic resistance determinants. Microorganisms. 2016;4(1):14. doi: 10.3390/microorganisms4010014

15. Poole K. Efflux-mediated antimicrobial resistance. J Antimicrob Chemother. 2005;56(1):20-51. doi: 10.1093/jac/dki171

16. Morita $Y$, Murata T, Mima T, et al. Induction of mexCD-oprJ operon for a multidrug efflux pump by disinfectants in wild-type Pseudomonas aeruginosa PAO1. J Antimicrob Chemother. 2003;51(4):991-994. doi: $10.1093 / \mathrm{jac} / \mathrm{dkg} 173$

17. Sanchez P, Moreno E, Martinez JL. The biocide triclosan selects Stenotrophomonas maltophilia mutants that overproduce the SmeDEF multidrug efflux pump. Antimicrob Agents Chemother. 2005;49(2):781-782. doi: 10.1128/AAC.49.2.781-782.2005

18. Huet AA, Raygada JL, Mendiratta K, Seo SM, Kaatz GW. Multidrug efflux pump overexpression in Staphylococcus aureus after single and multiple in vitro exposures to biocides and dyes. Microbiology. 2008;154(10):3144-3153. doi: 10.1099/ mic.0.2008/021188-0

19. El-Hadedy D, El-Nour SA. Identification of Staphylococcus aureus and Escherichia coli isolated from Egyptian food by conventional and molecular methods. Journal of Genetic Engineering and Biotechnology. 2012;10(1):129-135. doi: 10.1016/j. jgeb.2012.01.004

20. Clinical Laboratory Standards Institute. Performance standards for antimicrobial susceptibility testing; 19 th informational supplement. Document M100-S19. Clinical Laboratory Standards Institute. 2009; Wayne, PA.

21. Curiao $\mathrm{T}$, Marchi E, Viti C, et al. Polymorphic variation in susceptibility and metabolism of triclosan-resistant mutants of Escherichia coli and Klebsiella pneumoniae clinical strains obtained after exposure to biocides and antibiotics. Antimicrob Agents Chemother. 2015;59(6):3413-3423. doi: 10.1128/AAC.00187-15

22. Soumet C, Meheust D, Pissavin C, et al. Reduced susceptibilities to biocides and resistance to antibiotics in food-associated bacteria following exposure to quaternary ammonium compounds. J Appl Microbiol. 2016;121(5):1275-1281. doi: 10.1111/jam.13247

23. Huguet A, Pensec J, Soumet C. Resistance in Escherichia coli: variable contribution of efflux pumps with respect to different fluoroquinolones. J Appl Microbiol. 2013;114(5):1294-1299. doi: 10.1111/jam.12156

24. Gomes DF, da Silva Batista JS, Rolla AAP, et al. Proteomic analysis of free-living Bradyrhizobium diazoefficiens: highlighting potential determinants of a successful symbiosis. BMC genomics. 2014;15(1):643. doi: 10.1186/1471-2164-15-643

25. Pfaffl MW. A new mathematical model for relative quantification in real-time RT-PCR. Nucleic Acids Res. 2001;29(9):e45. doi: 10.1093/nar/29.9.e45

26. Dorak M. Real Time PCR, London. Taylor \& Francis. 2006. doi: $10.4324 / 9780203967317$
27. Levy SB. Antibacterial household products: cause for concern. Emerg Infect Dis. 2001;7(3 Suppl):512-515. doi: 10.3201/eid0707.017705

28. Russell AD. Mechanisms of bacterial insusceptibility to biocides. Am J Infect Control. 2001;29(4):259-261. doi: 10.1067/mic.2001.115671

29. Gadea R, Glibota N, Pulido RP, Galvez A, Ortega E. Adaptation to biocides cetrimide and chlorhexidine in bacteria from organic foods: Association with tolerance to other antimicrobials and physical stresses. J Agric Food Chem. 2017;65(8):1758-1770. doi: 10.1021/acs.jafc.6b04650

30. Tezel U, Pavlostathis SG. Quaternary ammonium disinfectants: microbial adaptation, degradation and ecology. Curr Opin Biotechnol. 2015;33:296-304. doi: 10.1016/j.copbio.2015.03.018

31. Tkachenko O, Shepard J, Aris VM, et al. A triclosanciprofloxacin cross-resistant mutant strain of Staphylococcus aureus displays an alteration in the expression of several cell membrane structural and functional genes. Research in Microbiology. 2007;158(89):651-658. doi: 10.1016/j.resmic.2007.09.003

32. Heath RJ, Rock CO. A triclosan-resistant bacterial enzyme. Nature. 2000;406(6792):145-146. doi: $10.1038 / 35018162$

33. Cottell A, Denyer SP, Hanlon GW, Ochs D, Maillard JY. Triclosan-tolerant bacteria: changes in susceptibility to antibiotics. J Hosp Infect. 2009;72(1):71-76. doi: 10.1016/j.jhin.2009.01.014

34. Sonbol FI, El-Banna TE, Abd El-Aziz AA, El-Ekhnawy E. Impact of triclosan adaptation on membrane properties, efflux and antimicrobial resistance of Escherichia coli clinical isolates. J Applied Microbiol. 2019;126(3):730-739. doi: 10.1111/jam.14158

35. Romanova NA, Wolffs PFG, Brovko LY, Griffiths MW. Role of efflux pumps in adaptation and resistance of Listeria monocytogenes to benzalkonium chloride. Appl Environ Microbiol. 2006;72(5):3498-3503. doi: 10.1128/AEM.72.5.3498-3503.2006

36. Braoudaki M, Hilton AC. Adaptive resistance to biocides in Salmonella enterica and Escherichia coli 0157 and cross-resistance to antimicrobial agents. J Clin Microbiol. 2004;42(1):73-78. doi: 10.1128/ JCM.42.1.73-78.2004

37. Seaman PF, Ochs D, Day MJ. Small-colony variants: a novel mechanism for triclosan resistance in methicillinresistant Staphylococcus aureus. J Antimicrob Chemother. 2007;59(1):43-50. doi: 10.1093/jac/dk|450 38. Condell O, Iversen C, Cooney S, et al. Efficacy of biocides used in the modern food industry to control Salmonella enterica, and links between biocide tolerance and resistance to clinically relevant antimicrobial compounds. Appl Environ Microbiol. 2012;78(9):30873097. doi: 10.1128/AEM.07534-11

39. Davin-Regli A. Cross-resistance between biocides and antimicrobials: an emerging question. Revue scientifique et technique (International Office of Epizootics). 2012;31(1):89-104. doi: 10.20506/ rst.31.1.2099

40. Nhung NT, Thuy CT, Trung NV, et al. Induction of antimicrobial resistance in Escherichia coli and nontyphoidal Salmonella strains after adaptation to 
disinfectant commonly used on farms in Vietnam. Antibiotics. 2015;4(4):480-494. doi: 10.3390/ antibiotics 4040480

41. Hooper DC. Emerging mechanisms of fluoroquinolone resistance. Emerg Infect Dis. 2001;7(2):337-341. doi: 10.3201/eid0702.010239

42. Poole K. Efflux-mediated resistance to fluoroquinolones in gram-positive bacteria and the mycobacteria. Antimicrob Agents Chemother. 2000;44(10):25952599. doi: 10.1128/AAC.44.10.2595-2599.2000

43. Cohen SP, Hooper DC, Wolfson JS, Souza KS, McMurry LM, Levy SB. Endogenous active efflux of norfloxacin in susceptible Escherichia coli. Antimicrob Agents Chemother. 1988;32(8):1187-1191. doi: 10.1128/ AAC.32.8.1187

44. Bohnert JA, Schuster S, Fahnrich, E, Trittler, R, Kern WV. Altered spectrum of multidrug resistance associated with a single point mutation in the Escherichia coli RND-type MDR efflux pump YhiV (MdtF). J Antimicrob Chemother. 2007;59(6):1216-1222. doi: 10.1093/jac/ $\mathrm{dk} \mid 426$

45. Maseda H, Hashida $Y$, Konaka R, Shirai A, Kourai H. Mutational upregulation of a resistance-nodulationcell division-type multidrug efflux pump, SdeAB, upon exposure to a biocide, cetylpyridinium chloride, and antibiotic resistance in Serratia marcescens. Antimicrob Agents Chemother. 2009;53(12):52305235. doi: 10.1128/AAC.00631-09

46. Fernandez-Cuenca F, Tomas M, Caballero-Moyano $\mathrm{FJ}$, et al. Reduced susceptibility to biocides in Acinetobacter baumannii: association with resistance to antimicrobials, epidemiological behaviour, biological cost and effect on the expression of genes encoding porins and efflux pumps. I Antimicrob Chemother. 2015;70(12):3222-3229. doi: 10.1093/jac/dkv262 